\title{
EFFECT OF YOGA MODULE CONSISTING HATHAYOGA, SURYANAMASKAR AND YOGANIDRA ON IMPROVEMENT OF PULMONARY FUNCTION PARAMETERS IN NORMAL SUBJECTS
}

\author{
Mini K1, Vasudevan M. N2, Kalyani Sen ${ }^{3}$ \\ ${ }^{1}$ Additional Professor, Department of Physiology, Government Medical College, Trissur. \\ ${ }^{2}$ Lecturer ETC, Mannuthy. \\ 3Professor, Department of Physiology, Gokulam Medical College, Trivandrum.
}

\section{ABSTRACT}

\section{BACKGROUND}

The importance of yoga related to medicine is mainly getting a method of mental relaxation in view of the tremendous increase in the stress and strain of daily life, especially in urban areas. The studies by K. N. Udupa shows that the postural exercises described in yoga are isometric exercise and the results of these exercise are different from that of yogic exercise. Present study is conducted to probe into effectiveness of yoga in improving pulmonary functions.

This study is conducted to probe into effectiveness of Yoga in improving pulmonary functions. The studies related to yoga and pulmonary function tests are mainly conducted in asthmatic patients so far. In this paper, we are dealing the effects of Yoga on the pulmonary function in normal subjects.

\section{MATERIALS AND METHODS}

Pulmonary functions namely vital capacity, expiratory reserve volume, inspiratory capacity, forced vital capacity, FEV1, ratio of FEV1/FVC. Peak expiratory flow rate and maximum voluntary ventilation of normal subjects before and after a yoga module practiced for 40 days are compared. The above parameters found out accurately by using small computerised spirometer from JAEGER flow screen. Paired ' $t$ ' test was used to find out the degree of significance in each pulmonary function.

\section{RESULTS}

There was highly significant increase in FVC, FEV1 and MVV after yoga practice. The change in other pulmonary function parameters were not statistically significant.

\section{CONCLUSION}

The pulmonary functions mainly FVC, FEV1 and MVV can be increased by daily practice of Yoga and Yoga can be useful as a means of promoting positive health of common man.

\section{KEYWORDS}

Yoga module, Pulmonary Function Tests.

HOW TO CITE THIS ARTICLE: Mini K, Vasudevan MN, Sen K. Effect of yoga module consisting hathayoga, suryanamaskar and yoganidra on improvement of pulmonary function parameters in normal subjects. J. Evolution Med. Dent. Sci. 2017;6(18):14441449, DOI: $10.14260 /$ Jemds/2017/315

\section{BACKGROUND}

Yoga is one of the six orthodox systems of Indian philosophy, the importance of Yoga related to medicine is mainly getting a method of mental relaxation in view of the stress and strain of life. In recent times, there has been intense search for alternate measures other than drugs to prevent psychosomatic diseases. For this Yoga and several other methods like 'autogenic training' in Germany, Zen meditation in Japan has become popular. It is high time that we should conduct research into various aspects of Yoga. This study is conducted to probe into effectiveness of Yoga in improving pulmonary functions. The studies related to yoga and pulmonary function tests are mainly conducted in asthmatic patients so far. In this paper, we are dealing with the effects of Yoga on the pulmonary function in normal subjects.

Financial or Other, Competing Interest: None.

Submission 19-12-2016, Peer Review 17-02-2017,

Acceptance 23-02-2017, Published 02-03-2017.

Corresponding Author:

Dr. Mini $K$,

Additional Professor

Department of Physiology,

Government Medical College, Thrissur.

E-mail: melminivasudevan@gmail.com

DOI: $10.14260 /$ jemds $/ 2017 / 315$
The following Research Works on Effects of Yoga on Ventilator Function provided Guidelines for the Study-

1. Yoga therapy in chronic bronchitis, Behera D.(1)

2. Recovery from stress in two different postures and in Shavasana- a yogic relaxation posture.(2)

3. Clinical study of yoga techniques in university students with asthma: a controlled study. Relaxation posture.(3)

4. Study of pulmonary and autonomic functions of asthma patients after yoga training.(4)

5. Effect of short-term 'Pranayama' practice on breathing rate and ventilatory functions of lung.

\section{MATERIALS AND METHODS}

The present study was done to find out the changes taking place in pulmonary functions of normal subjects after a course of yoga practice of 40 days. Screening of all subjects for the study were done by excluding any major diseases like tuberculosis, diabetes and personal history of alcoholism, smoking, etc. The study group included normal subjects undergoing yoga training under guidance of Sathyananda Yoga Research Centre, Calicut; 40 individuals were selected and the following pulmonary functions were done prior to and after a period of 40 days 1 hour Yoga practice. 


\section{Sample Size and Sampling Technique}

Sample size is taken as 40. Subjects were selected from the persons practicing Yoga in the Sathyananda Yoga Research Centre, Calicut.

\section{Inclusion Criteria}

Subjects doing the above Yoga module under supervision in the Sathyananda Yoga Centre who are willing for the study. The pulmonary function tests of the subjects must be within the normal limits before Yoga practice.

\section{Exclusion Criteria}

- Subjects with abnormal pulmonary functions.

- Subjects receiving any medication for pulmonary diseases.

- $\quad$ Subjects following any other lifestyle modifications other than the above-mentioned yoga module in the same period.

- Tuberculosis, Diabetes mellitus and History of smoking or alcoholism.

\section{Pulmonary Function Tests}

1) Vital capacity, 2) Expiratory reserve volume, 3) Inspiratory capacity, 4) Forced vital capacity, 5) Forced vital capacity in 1 sec, 6) FEV1/FVC ratio, 7) PEFR and 8) MVV.

The Yoga Package included the following Asanas Practiced Regularly for 1 Hour by all Members of the Study Group

1. Vajrasana,

2. Sasankasana,

3. Katichakrasana,

4. Ardha Katichakrasana,

5. Soorya Namaskara,

6. Parswa Thrikonasana,

7. Parvathasana,

8. Merudandasana,

9. Kandharasana,

10. Pavanamukthasana,

11. Makarasana,

12. Bhujangasana,

13. Ardha Salabhasana,

14. Salabhasana,

15. Dhanurasana,

16. Ushtrasana,

17. Janusishasana,

18. Paschimothanasana,

19. Vakrasana,

20. Ardhamatsendrasana,

21. Vipareethakarani Asana,

22. Sarvangasana,

23. Matsyasana,

24. Pranayamam,

25. Kapalabhathi,

26. Yoganidra - Relaxation.

\section{Selection of Equipment}

Equipment selection is done and the instrument used was a portable small computerised spirometer from Jaeger named "Flow screen." A pneumotach is attached to the handle. An elbow piece extension is connected to the side of the pneumotach to which the mouth piece is attached. The pneumotach registers the measuring values, which is displayed by computer system on the screen.

\section{Procedure}

Biodata was collected from the subject. Age was confirmed by obtaining the date of birth. No subject was tested at a time when he or she had an upper respiratory infection. All tests were done at the same time of day to avoid possible diurnal variations.

Physical parameters were then recorded. Standing height in $\mathrm{cm}$ and weight in kilograms. The pneumotach is calibrated once a day using the calibration pump provided. All tests were performed in the sitting position.

After subject was comfortably seated, he or she was instructed to loosen any tight clothing. The procedure was explained in simple terms. Before the beginning of each test, the appropriate technique demonstrated. A disposable mouth piece was used for each subject. The mouthpiece was positioned, so that the subject's chin was slightly elevated and neck extended. After the insertion of mouthpiece, a check was made to ensure that no leaks were present. The subject was exhorted to make a maximal effort for each test and was closely watched to ensure that he or she maintained an airtight seal between the lips and mouthpiece of the instrument.

\section{Spirometry}

First the subject's data were entered, i.e. ID No: Name, Date of Birth, Sex, Height and Weight. Then the required measurement was called up from the menu. We first do the spirometry (F1) for finding out vital capacity, expiratory reserve volume and inspiratory capacity. The subject was seated comfortably with the nose clip in place. The subject was then asked to breathe via the mouth piece attached to the pneumotach. At first he was asked to breathe slowly. This ensures that the subject is in a state of rest and establishes the resting end expiratory level. This level serves as a point of reference for the subsequent measurements. Then the subject was urged to inspire fully and then after reaching a plateau at maximum inspiration to expire maximally. The expiration was performed as deeply as possible, but slowly. Three consecutive determinations were done and VC, ERV and IC recorded from the best of the 3 tests.

\section{Flowmetry}

The measurement flow/volume (F3) is called up from the menu. Posture of the subject is same as that of the previous test. The subject was asked to completely exhale; then inhale deeply as possible; then breathe out as rapidly, forcefully and completely as possible. If the expiration is less than 1 second, the procedure should be repeated to find out the results. The end key is pressed and the parameters, VC, FVC, FEV1, FEV1/FVC and PEFR are recorded from the screen. The reference predicted values are obtained with the percentage of predicted value from the screen.

\section{Measurement of MVV}

To measure MVV the subject was instructed to breathe deeply and rapidly as possible, the maximal possible amount of air over a $12 \mathrm{sec}$ interval after applying the nose clip. After $12 \mathrm{sec}$, the program is ended automatically and the parameter is extrapolated to 1 minute and shown on the screen with the actual/predicted value comparison. 


\section{RESULTS}

Pulmonary function tests namely vital capacity, expiratory reserve volume, inspiratory capacity, forced vital capacity, FEV1 and FEV. PEFR and MVV were also measured before and after yoga.

\section{Paired ' $\mathrm{t}$ ' Test}

Standard deviation of $\mathrm{Z}$ value was calculated using the formula $\mathrm{Sz}=$

$$
\sqrt{\frac{\sum(\mathbf{z}-\mathbf{z})^{2}}{\mathrm{n}-1}}
$$

where ' $z$ ' is difference in each parameter after yoga.
$\mathrm{Z}=$ mean value of difference in each parameter. The mean $\mathrm{Z}$ of each parameter was obtained by summing up the change in parameter due to yoga and dividing it by the number of subject in the corresponding group, standard error was found out using the formula $S E=S z \sqrt{n}$.

where $\mathrm{Sz}=$ standard deviation-

$\mathrm{N}=$ no. of subjects.

Paired ' $t$ ' test was employed to find out the significance and ' $\mathrm{t}$ ' value.

\begin{tabular}{|c|c|c|c|c|c|c|c|}
\hline $\begin{array}{c}\text { Increase } \\
\text { in VC (L) }\end{array}$ & $\begin{array}{c}\text { Increase } \\
\text { in ERV (L) }\end{array}$ & $\begin{array}{c}\text { Increase } \\
\text { in IC (L) }\end{array}$ & $\begin{array}{c}\text { Increase } \\
\text { in FVC (L) }\end{array}$ & $\begin{array}{c}\text { Increase } \\
\text { in FEV1 (L) }\end{array}$ & $\begin{array}{c}\text { Increase in } \\
\text { FEV1/FVC (L/min) }\end{array}$ & $\begin{array}{c}\text { Increase in } \\
\text { PEFR (L/min) }\end{array}$ & $\begin{array}{c}\text { Increase in } \\
\text { MVV (L/min) }\end{array}$ \\
\hline $0.565 \pm .167$ & $239 \pm .137$ & $0.26 \pm .25$ & $.92 \pm .145$ & $.576 \pm .156$ & $2.59 \pm 2.8$ & $0.95 \pm .53$ & $26.77 \pm 4.2$ \\
\hline $\mathrm{SD}=1.05$ & $\mathrm{SD}=.86$ & $\mathrm{SD}=1.5$ & $\mathrm{SD}=.92$ & $\mathrm{SD}=98$ & $\mathrm{SD}=17.72$ & $\mathrm{SD}=3.35$ & 26.64 \\
\hline $\mathrm{t}=3.38$ & $\mathrm{t}=1-74$ & $\mathrm{t}=1.03$ & $\mathrm{t}=6.34$ & $\mathrm{t}=3.69$ & $\mathrm{t}=.925$ & $\mathrm{t}=1.79$ & $\mathrm{t}=6.34$ \\
\hline $\mathrm{P}<.01 \mathrm{HS}$ & $\mathrm{P}>.05 \mathrm{NS}$ & $\mathrm{P}>.05 \mathrm{NS}$ & $\mathrm{P}<.01 \mathrm{HS}$ & $\mathrm{P}<.01 \mathrm{HS}$ & $\mathrm{P}>.05 \mathrm{NS}$ & $\mathrm{P}>.05 \mathrm{NS}$ & $\mathrm{P}<.01 \mathrm{HS}$ \\
\hline
\end{tabular}

Table 1 shows the difference in different pulmonary function test parameters after yoga. The vital capacity observed in the study was in the range of $1.56 \mathrm{~L}-6.92 \mathrm{~L}$ before Yoga and 1.8 L - 6.1 L after Yoga. The mean increase in vital capacity was $0.565 \pm 0.165(\mathrm{SD}=1.15$, t value $=3.58)$. The increase in vital capacity after Yoga is highly significant.

ERV was noticed to be in the range of $0.1 \mathrm{~L}-4.3 \mathrm{~L}$, and it changed to $0.15 \mathrm{~L}-4.6 \mathrm{~L}$ after Yoga. The mean difference in ERV is $0.239 \pm 0.137$ and $.92 \mathrm{SD}$ is 0.86 . T value obtained is 1.74. This is not significant ( $p>0.05)$.

Inspiratory capacity is in the range of $0.21 \mathrm{~L}-8.52 \mathrm{~L}$, changed to the range of $0.22-51 \mathrm{~L}$ after Yoga. The mean increase in IC was $0.26 \pm 0.25$ and the SD is 1.5 . T value obtained is 1.03 and so the change in IC after Yoga is statistically not significant ( $p>.05$ ).

Forced vital capacity was found in the range of $1.08 \mathrm{~L}$ $9.64 \mathrm{~L}$ and it increased to the range of $2.48 \mathrm{~L}-9.92 \mathrm{~L}$ after Yoga. The mean increase in FVC is $0.92 \pm .145$ and the SD is 0.92 . $\mathrm{T}$ value obtained is 6.34. This increase in FVC is highly significant statistically $(\mathrm{p}<0.01)$.

Forced vital capacity in 1 second was in the range of 1.12 $\mathrm{L}-5.3 \mathrm{~L}$ after Yoga. Mean increase in FEV1 is $0.576 \pm 1.56$ and the SD is 0.98 . T value obtained is 3.69 and therefore increase in FEV1 is highly significant $(\mathrm{p}<0.01)$.

FEV1/FVC - The ratio of FEV1/FVC before Yoga was in the range of $33.1 \mathrm{~L}-98.9 \mathrm{~L}$. It changed to the range of $49.4 \mathrm{~L}$ 100.3 L after Yoga. Mean increase in FEV1/FVC ratio was 2.59 \pm 2.8 (SD is 17.72 , $\mathrm{t}$ value 0.925 ). The change in FEVI/FVC ratio after Yoga is not significant ( $\mathrm{p}>0.05$ ).

Peak expiratory flow rate was in the range of $1.12 \mathrm{~L} / \mathrm{min}$ $10.4 \mathrm{~L} / \mathrm{min}$, which changed to the range of $1.25 \mathrm{~L} / \mathrm{min}-14.3$ $\mathrm{L} / \mathrm{min}$ after Yoga. The mean increase in PEFR is $0.95 \pm .53$ (SD is 3.35), $t$ value obtained is 1.79 . This difference is not statistically significant $(\mathrm{p}>0.05)$.
Maximum voluntary ventilation obtained was in the range of $44 \mathrm{~L} / \mathrm{min}-182 \mathrm{~L} / \mathrm{min}$ before yoga, which increased to 62 $\mathrm{L} / \mathrm{min}-192 \mathrm{~L} / \mathrm{min}$ after yoga. The mean increase in MVV is $26.77 \pm 4.2$ and the SD is 26.64 . T value obtained is 6.34 . This shows highly significant ( $\mathrm{p}<0.01$ ) increase in MVV following the practice of Yoga.

\begin{tabular}{|c|c|c|c|c|c|}
\hline & \multicolumn{4}{|c|}{$\begin{array}{c}\text { No. of Individuals } \\
\text { in Different Groups }\end{array}$} \\
\hline $\begin{array}{c}\text { Change in } \\
\text { Parameters in Litres }\end{array}$ & VC & FVC & FEVI & $\begin{array}{c}\text { MVV } \\
\text { (L/min) }\end{array}$ \\
\hline Group 1 & Decrease & 6 & 1 & 7 & 2 \\
\hline Group 2 & No Change & 0 & 0 & 2 & 7 \\
\hline Group 3 & Increase up to 0.5 & 16 & 13 & 14 & 5 \\
\hline Group 4 & Increase 0.5 to 1 & 8 & 15 & 9 & 9 \\
\hline Group 5 & $\begin{array}{c}\text { Increase } \\
\text { more than 1 }\end{array}$ & 10 & 11 & 8 & 17 \\
\hline $\begin{array}{c}\text { Table 2. Frequency of Individuals in Different Groups } \\
\text { according to the Changes in Pulmonary Function } \\
\text { Parameters after Yoga }\end{array}$ \\
\hline
\end{tabular}

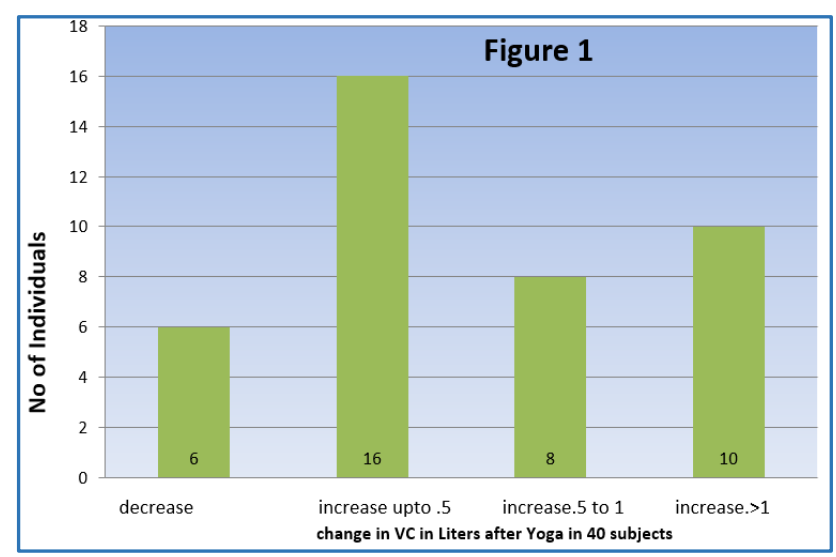



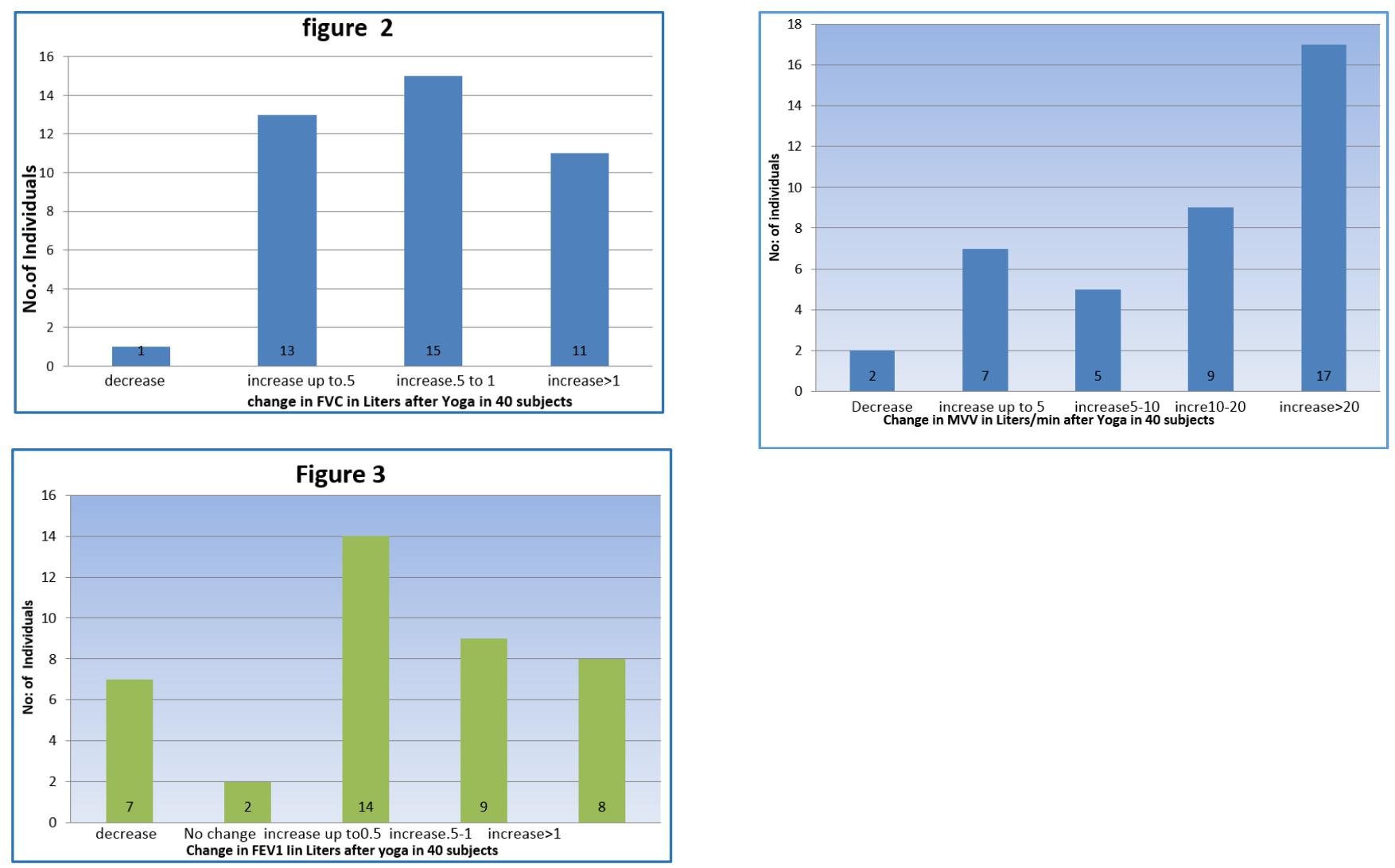

\begin{tabular}{|c|c|c|c|c|c|c|c|c|}
\hline $\begin{array}{l}\text { Sl. } \\
\text { No. }\end{array}$ & $\begin{array}{l}\text { Increase } \\
\text { in VC (L) }\end{array}$ & $\begin{array}{c}\text { Increase in } \\
\text { ERV (L) }\end{array}$ & $\begin{array}{l}\text { Increase } \\
\text { in IC (L) }\end{array}$ & $\begin{array}{l}\text { Increase } \\
\text { in FVC (L) }\end{array}$ & $\begin{array}{c}\text { Increase in } \\
\text { FEV1 (L) } \\
\end{array}$ & $\begin{array}{c}\text { Increase in } \\
\text { FEVI/FVC (L) }\end{array}$ & $\begin{array}{c}\text { Increase in } \\
\text { PEFR (L/min) }\end{array}$ & $\begin{array}{c}\text { Increase in } \\
\text { MVV (L/min) }\end{array}$ \\
\hline 1 & .32 & -0.05 & 0.53 & .72 & .76 & 5.8 & -.76 & 2.1 \\
\hline 2 & 0.48 & 1.83 & 1.27 & .68 & 1.64 & 35 & 7.21 & 11.9 \\
\hline 3 & .55 & 0.22 & 0.67 & .47 & -0.02 & 4 & .26 & 1.5 \\
\hline 4 & .06 & .06 & 0.01 & .66 & 0.2 & 1.9 & .27 & .51 \\
\hline 5 & .89 & 1.24 & 2.68 & 1.84 & -0.16 & $-25-9$ & -.14 & 64.6 \\
\hline 6 & 3.81 & 0.16 & 3.65 & 3.92 & 4.04 & 30.8 & 13.99 & 101.4 \\
\hline 7 & 0.16 & -0.95 & 0.04 & .56 & .84 & 32.6 & 3 & 4.3 \\
\hline 8 & 0.26 & 0.65 & 6.68 & 2.12 & 1.72 & 1.5 & 1.12 & -1.9 \\
\hline 9 & 0.15 & 0 & 0.08 & .27 & 0 & 11 & 1.9 & 1 \\
\hline 10 & 0.72 & .10 & 0.2 & .5 & 0.5 & 2 & 0.79 & 14.5 \\
\hline 11 & .44 & -.42 & 0.81 & .16 & 0.48 & 5.3 & -0.11 & 34.4 \\
\hline 12 & 1.41 & -0.12 & 1.53 & 1.52 & 0.92 & 2.4 & 2.32 & 51.1 \\
\hline 13 & 0.44 & -0.62 & 1.07 & .72 & 0.68 & -0.9 & -0.94 & 34.6 \\
\hline 14 & 1.16 & 1.72 & 0.01 & 1.47 & 0.23 & 6 & 0.26 & 11 \\
\hline 15 & 1.39 & -0.19 & 1.57 & -0.16 & -0.6 & -45.3 & -2.16 & 45.4 \\
\hline 16 & 1.74 & -.08 & 1.78 & 1.52 & 1.04 & -16.1 & 0.28 & 40.9 \\
\hline 17 & 1.41 & 0.76 & 0.65 & 1.16 & 1.2 & 1.9 & 4.73 & 56.5 \\
\hline 18 & 2.22 & .47 & 2.23 & 0.68 & 1.32 & -16 & 2.69 & 66.6 \\
\hline 19 & 1.48 & -.03 & 1.43 & 1.36 & 1.36 & 2.1 & 1.32 & 40.5 \\
\hline 20 & 2.82 & 1.03 & 1.79 & 4.2 & 3.4 & 19.9 & 4.51 & 69.5 \\
\hline 21 & 0.74 & -1.12 & .66 & .28 & 0.32 & 16.3 & 0.96 & 65 \\
\hline 22 & 0.24 & -0.36 & .59 & 0.01 & 0.16 & 3.7 & 0.79 & 15.3 \\
\hline 23 & 0.03 & 0.14 & 0.11 & 0.44 & 0.48 & 1.5 & 0.46 & 17.6 \\
\hline 24 & 1.15 & 1.11 & .03 & 2.12 & 0.72 & -16.4 & 0.77 & 34 \\
\hline 25 & 0.2 & 0.2 & .17 & 0.37 & 0.5 & 2.8 & 2 & 3 \\
\hline 26 & .09 & 0.2 & .39 & .72 & 0.7 & 4.8 & 1.48 & 21 \\
\hline 27 & -1.6 & -1.93 & .34 & .6 & 0.72 & 34.6 & 2.42 & 12.2 \\
\hline 28 & 2.14 & -0.5 & 0.66 & .6 & 0.48 & 31.2 & 2.37 & 11 \\
\hline 29 & 0.42 & -0.07 & 1.26 & .97 & 0.06 & 16.9 & 0.1 & 4.6 \\
\hline 30 & 0.27 & .51 & 0,24 & 1.28 & -0.92 & -28.3 & -4.82 & -9.3 \\
\hline 31 & 0.41 & .65 & 0.25 & 0.81 & 0.32 & -8.1 & -4.9 & 10 \\
\hline 32 & 0.76 & -3 & 0.97 & 0.7 & 0 & 7 & -0.2 & 6 \\
\hline 33 & 0.3 & .35 & 0.05 & 0.19 & -0.76 & -29.6 & -2.81 & 17.2 \\
\hline 34 & 0.11 & .31 & .86 & 0.02 & 0.25 & 17 & 0.14 & 12.3 \\
\hline
\end{tabular}




\begin{tabular}{|l|c|c|c|c|c|c|c|c|}
\hline 35 & 1 & -0.38 & 1.1 & 1 & 1 & 3.3 & 3.34 & 10 \\
\hline 36 & 0.15 & -1.26 & 1.4 & 0.4 & -1.76 & -9.7 & -6.01 & 8.3 \\
\hline 37 & .55 & .35 & 0.97 & 0.11 & 0.43 & 0.7 & 0.93 & 8 \\
\hline 38 & 0.98 & 2.11 & 1.13 & 0.92 & 0.28 & -9.2 & -3.55 & 82 \\
\hline 39 & 0.41 & .43 & 0.84 & 0.1 & -0.08 & 8.7 & -0.14 & 44.61 \\
\hline 40 & 1.08 & 2.44 & 0.41 & 0.8 & 0.6 & -1.7 & 3.9 & 48 \\
\hline \multicolumn{7}{|c|}{ Table 3. Change in PFT after Yoga in Normal Subjects } \\
\hline
\end{tabular}

\begin{tabular}{|c|c|c|c|c|c|c|c|}
\hline $0.565 \pm .167$ & $239 \pm .137$ & $0.26 \pm .25$ & $.92 \pm .145$ & $.576 \pm .156$ & $2.59 \pm 2.8$ & $0.95 \pm .53$ & $26.77 \pm 4.2$ \\
\hline $\mathrm{SD}=1.05$ & $\mathrm{SD}=.86$ & $\mathrm{SD}=1.5$ & $\mathrm{SD}=.92$ & $\mathrm{SD}=98$ & $\mathrm{SD}=17.72$ & $\mathrm{SD}=3.35$ & 26.64 \\
\hline $\mathrm{t}=3.38$ & $\mathrm{t}=1-74$ & $\mathrm{t}=1.03$ & $\mathrm{t}=6.34$ & $\mathrm{t}=3.69$ & $\mathrm{t}=.925$ & $\mathrm{t}=1.79$ & $\mathrm{t}=6.34$ \\
\hline $\mathrm{P}<.01 \mathrm{HS}$ & $\mathrm{P}>.05 \mathrm{NS}$ & $\mathrm{P}>.05 \mathrm{NS}$ & $\mathrm{P}<.01 \mathrm{HS}$ & $\mathrm{P}<.01 \mathrm{HS}$ & $\mathrm{P}>.05 \mathrm{NS}$ & $\mathrm{P}>.05 \mathrm{NS}$ & $\mathrm{P}<.01 \mathrm{HS}$ \\
\hline
\end{tabular}

\section{DISCUSSION}

The ultimate aim of Yoga and Medical Science can be equated, so that the ultimate aim of both is attainment of physical and mental health of an individual.(1) During recent years, there is a renewed worldwide interest in yoga. In the present study, attempt is made to discover the meeting ground for points of mutual interests and how the practice of medicine and Yoga together can help in achieving optimum functioning of the body. This study is mainly aimed to evaluate the benefits achieved in pulmonary functions by the regular practice of yoga.

The pulmonary functions assessed are vital capacity; forced vital capacity, forced vital capacity in 1 second, maximum voluntary ventilation, expiratory reserve volume, inspiratory capacity, FEV1/FVC ratio and peak expiratory flow rate. Among these, significant increase was observed in the vital capacity, forced vital capacity, FEV1 and maximum voluntary ventilation. In a study conducted in sports teachers, (2) there was significant increase in PEFR, FVC and FEV1 (Though FEV1/FVC\% did not change). But increase in expiratory reserve volume, inspiratory capacity FEV1/FVC ratio and PEFR were not significant. In performing the yogic breathing, the subject while keeping his skeletal muscle relaxed and immobile exercises a close and continuous voluntary control over his respiratory muscle. The rate of breathing may be changed from $15-18 /$ min to $1-2 /$ min and the duration of expiration may be lengthened. All his help to override the usual stimuli to respiratory centres.(3) The increase in vital capacity is due to an increase in development of respiratory musculature due to regular exercise. This increase in vital capacity leads to increase in FVC also. While doing makarasana, the chest is expanded allowing an increased amount of air to enter the lungs. This helps to alleviate congestion of respiratory system. Similarly, Surya Namaskara accentuates the exchange of air to and from lungs. It also expands and opens up the alveoli and exercises the muscles of the chest wall. Ushtrasana expands the ribcage and associated muscles are made more supple facilitating deeper breathing. Dhanurasana realigns the back and thereby improves the breathing. This in turn leads to free flow of air through nasal passages. During Matsyasana the rib cage and lungs are given an accentuated stretch, which helps to improve the breathing by allowing the chest to expand to full capacity.(4) The study on the effect of short-term Yoga training programme on peak expiratory flow rate(5) shows an increase on PEFR after Yoga training. In a study by HS Nayar et al on the effects of yogic exercises on human physical efficiency,(6) '53 cadets of National Defence Academy were studied. They were divided into 3 groups namely 'one group doing routine NDA training the second group NDA training plus athletics and the third group NDA Training plus Yogic exercises. Yogic group had an additional improvement in breath holding time, VC and FEV1. The remaining 2 groups recorded only significant increase in $\mathrm{VC}$.

Thus, the above Yogic postures can improve the Breath holding time and pulmonary function tests such as Vital Capacity, FVC, FEV1 and MVV.

\section{CONCLUSION}

The present study leads to the following observations in relation to the pulmonary functions of subjects who practiced the Yoga module consisting Hathayoga, Suryanamaskar and Yoganidra regularly for 1 hour daily under supervision for a period of 40 days. A significant improvement in Vital Capacity, Forced Vital Capacity and FEV1 and MVV after yoga. The improvement in FEV1 indicates this yoga module may help the asthmatics to improve their lung functions. The importance of Yoga in modifying dynamic lung functions are also implicated by the significant increase in maximum voluntary ventilation after the practice of this Yoga module. The studies in relation to the improvement of pulmonary functions in COPD patients, for example in bronchial asthma patients can be planned in the future and more long-term studies are required in this field to make use of the benefits of Yoga in clinical practice.

\section{Limitations of the Study}

The study population included the individuals doing yoga from the Yoga Centre in Calicut. Sathyananda Yoga Research Centre was selected, since the maximum number of subjects performing a Yoga module regularly could be obtained from this centre. Sample size calculation could not be performed in a formal way because previous such studies were not available at the time of selection of subjects. The duration of study was 40 days only and long term studies are required for obtaining more reliable results in this field. A control group with similar pulmonary function parameters not performing yoga could not be kept for comparison.

\section{Acknowledgements}

I am extremely thankful to Yogacharya N Vijayaraghavan and his fellowmen, Satyananda Yoga Research Centre, Calicut, and the host of people who were subjects of this study for their whole hearted cooperation. My sincere thanks to Dr. Sanal 
Kumar, Secretary Medical Education Unit, Thrissur Medical College, for the encouragement given for the preparation of the paper.

\section{Abbreviations}

COPD - Chronic Obstructive Pulmonary Disease.

PFT - Pulmonary Function Test.

VC - Vital Capacity.

ERV - Expiratory Reserve Volume.

IC - Inspiratory Capacity.

FVC - Forced Vital Capacity.

FEV1/FVC - Forced Expiratory Volume 1/Forced Vital Capacity.

PEFR - Peak Expiratory Flow Rate.

MVV - Maximum Voluntary Ventilation.

MEFV - Maximum Expiratory Flow Volume Curve.

TLC - Total Lung Capacity.

RV - Residual Volume.

\section{REFERENCES}

[1] Behera D. Yoga therapy in chronic bronchitis. J Assoc Physicians India 1998;46(2):207-8.

[2] Bera TK, Gore MM, Oak JP. Recovery from stress in two different postures and in shavasana- a yogic relaxation posture. Indian J Physiol Pharmacol 1998;42(4):473-8.

[3] Vedanthan PK, Kesavalu LN, Murthy KC, et al. Clinical study of yoga techniques in university students with asthma: a controlled study. Allergy Asthma Proc 1998;19(1):3-9.

[4] Khanam AA, Sachdeva U, Guleria R, et al. Study of pulmonary and autonomic functions of asthma patients after yoga training. Indian J Physiol Pharmacol 1996;40(4):318-24.

[5] Joshi LN, Joshi VD, Gokhale LV. Effect of short term pranayam practice on breathing rate and ventilator functions of lung. Indian J Physiol Pharmacol 1992;36(2):105-8.

[6] Anand BK. Yoga and medical sciences. Indian Journal Physiol Pharmacol 1991;35(2):84-5. 